\title{
Differential expression of follistatin and FLRG in human breast proliferative disorders
}

\author{
Enrrico Bloise ${ }^{1,2}$, Henrique L Couto ${ }^{1}$, Lauretta Massai ${ }^{3}$, \\ Pasquapina Ciarmela ${ }^{4}$, Marzia Mencarelli ${ }^{5}$, Lavinia E Borges ${ }^{2}$, \\ Michela Muscettola5, Giovanni Grasso ${ }^{3}$, Vania F Amaral6, \\ Geovanni D Cassali6, Felice Petraglia ${ }^{2}$ and Fernando M Reis*1
}

\begin{abstract}
Address: ${ }^{1}$ Departments of Obstetrics \& Gynecology and Physiology, Federal University of Minas Gerais, Belo Horizonte, Brazil, ${ }^{2}$ Department of Obstetrics and Gynecology, University of Siena, Siena, Italy, ${ }^{3}$ Department of Biomedical Sciences, University of Siena, Siena, Italy, ${ }^{4}$ Department of Molecular Pathology and Innovative Therapies, Polytechnic University of Marche, Ancona, Italy, ${ }^{5}$ Department of Physiology, University of Siena, Siena, Italy and ' Department of Pathology, Federal University of Minas Gerais, Belo Horizonte, Brazil

Email: Enrrico Bloise - bloise2@unisi.it; Henrique L Couto - enriquecouto@hotmail.com; Lauretta Massai - massai2@unisi.it; Pasquapina Ciarmela - iopina@yahoo.com; Marzia Mencarelli - mencarelli4@unisi.it; Lavinia E Borges - laviniaeb@hotmail.com; Michela Muscettola - muscettola@unisi.it; Giovanni Grasso - grasso@unisi.it; Vania F Amaral - tomasafb@uai.com.br;

Geovanni D Cassali - cassalig@icb.ufmg.br; Felice Petraglia - petraglia@unisi.it; Fernando M Reis* - reis@medicina.ufmg.br

* Corresponding author
\end{abstract}

Published: 9 September 2009

BMC Cancer 2009, 9:320 doi:10.1 I86/I47I-2407-9-320
Received: 3 February 2009

Accepted: 9 September 2009

This article is available from: http://www.biomedcentral.com//47I-2407/9/320

(c) 2009 Bloise et al; licensee BioMed Central Ltd.

This is an Open Access article distributed under the terms of the Creative Commons Attribution License (http://creativecommons.org/licenses/by/2.0), which permits unrestricted use, distribution, and reproduction in any medium, provided the original work is properly cited.

\begin{abstract}
Background: Activins are growth factors acting on cell growth and differentiation. Activins are expressed in high grade breast tumors and they display an antiproliferative effect inducing G0/GI cell cycle arrest in breast cancer cell lines. Follistatin and follistatin- related gene (FLRG) bind and neutralize activins. In order to establish if these activin binding proteins are involved in breast tumor progression, the present study evaluated follistatin and FLRG pattern of mRNA and protein expression in normal human breast tissue and in different breast proliferative diseases.
\end{abstract}

Methods: Paraffin embedded specimens of normal breast (NB $-n=8)$; florid hyperplasia without atypia $(F H-n=17)$; fibroadenoma (FIB $-n=17)$; ductal carcinoma in situ (DCIS $-n=10$ ) and infiltrating ductal carcinoma (IDC $-n=15)$ were processed for follistatin and FLRG immunohistochemistry and in situ hybridization. The area and intensity of chromogen epithelial and stromal staining were analyzed semi-quantitatively.

Results: Follistatin and FLRG were expressed both in normal tissue and in all the breast diseases investigated. Follistatin staining was detected in the epithelial cytoplasm and nucleus in normal, benign and malignant breast tissue, with a stronger staining intensity in the peri-alveolar stromal cells of FIB at both mRNA and protein levels. Conversely, FLRG area and intensity of mRNA and protein staining were higher both in the cytoplasm and in the nucleus of IDC epithelial cells when compared to NB, while no significant changes in the stromal intensity were observed in all the proliferative diseases analyzed.

Conclusion: The present findings suggest a role for follistatin in breast benign disease, particularly in FIB, where its expression was increased in stromal cells. The up regulation of FLRG in IDC suggests a role for this protein in the progression of breast malignancy. As activin displays an anti-proliferative effect in human mammary cells, the present findings indicate that an increased FST and FLRG expression in breast proliferative diseases might counteract the antiproliferative effects of activin in human breast cancer. 


\section{Background}

Activins (A, B and $A B$, composed respectively of two $\beta A$ subunits, two $\beta B$ subunits and one $\beta A$ and one $\beta B$ subunit) are pleiotropic secreted polypeptides. They belong to the transforming growth factor- $\beta$ (TGF- $\beta$ ) superfamily and exhibit regulatory roles over important cell cycle events such as cell proliferation, differentiation, apoptosis and consequently tumor growth [1]. Previously, we reported activin/inhibin localization in human breast [2] and increased expression of dimeric activin A in breast cancer tissue homogenates [3]. Importantly, we also demonstrated that in postmenopausal women with breast cancer, activin A levels in serum were increased and subsequently decreased after mastectomy, suggesting that a major source had been removed [3]. Despite this, activin's signal transduction components are down-regulated in high-grade breast cancer at protein level, as well as activin $\beta B$ subunit, demonstrating that even though activin $A$ is abundantly available in breast carcinoma, its transduction pathway is decreased [4]. Local inhibins are not increased either $[2,4]$, leading to the question of why activin $A$ is unable to induce its signaling pathway and, consequently, perform its biological functions. Additionally, activins display an antiproliferative effect in human breast cancer cells by arresting them in the G0/G1 cell cycle phase $[5,6]$, an effect that may be counteracted by estrogen, since a crosstalk between activin and estrogen has been demonstrated [7].

Activins signal through cell-surface receptors that display predicted serine/threonine kinase activity. Activins bind selectively to ActRIB and ActRIIA receptors, while ActRIA and ActRIIB have been demonstrated to bind promiscuously to other TGF- $\beta$ components $[8,9]$. The receptor-activated Smads 2 and 3 bind to the common smad 4 , forming a complex that moves towards the nucleus, where it can modulate gene expression and promote activins biological effects [10]. These biological events are inhibited mainly by the glycosylated single-chain proteins, follistatin (FST) and follistatin-related protein, encoded by follistatin-related gene (FLRG) [10]. Besides activins, FST also binds and neutralizes other TGF- $\beta$ growth factors such as myostatin and bone morphogenetic proteins (BMPs) 2, 4, 6 and 7 [11-13], while FLRG has been demonstrated to neutralize myostatin $[14,15]$.
Recently, a number of reports showed that the activin/FST system plays important roles in the progression of malignant diseases by regulating cell proliferation or angiogenesis [16]. Coherently with activin's role in breast carcinogenesis, FST and FLRG have also been associated with tumorigenesis of different tissues [17-19]. Specifically in the mammary gland of immunodeficient SCID mice, FST-expressing R30C tumor displayed increased angiogenesis but a higher susceptibility to undergo serum starvation-induced apoptosis and therefore limiting tumor progression properties [20]. In high grade infiltrating ductal carcinomas (IDC), FST expression pattern was not altered, while FLRG expression was increased in the same tumor. Moreover, FLRG silencing through small interfering RNA (siRNA) induced significant tumor growth inhibition, an effect that was reversed upon the addition of exogenous FLRG [17], demonstrating that FLRG antagonizes activin effects in neoplastic cells.

In order to determine whether there is an aberrant expression of FLRG at different stages of tumor progression and also to determine if FST is involved in human breast tumor progression, we investigated the expression profile of activin binding proteins in different human breast proliferative diseases. Specifically, the aim of the present study was to define the expressional pattern of FST and FLRG in normal breast (NB) and in different cases of breast proliferative diseases such as: florid hyperplasia without atypia (FH), fibroadenoma (FIB), ductal carcinoma in situ (DCIS) and infiltrating ductal carcinoma (IDC).

\section{Methods \\ Subjects}

The breast samples used in this study were collected from 67 patients with ages ranging from 29 to 72 years (Table 1) regardless of the menstrual cycle phase or menopausal status, diagnosed between 2004 and 2006 in the Hermes Pardini Laboratories Pathology Service (Belo Horizonte, $M G$, Brazil). We included cases of normal breast (NB, $\mathrm{n}=$ $8)$, florid hyperplasia without atypia $(\mathrm{FH}, \mathrm{n}=17)$, fibroadenoma (FIB, $\mathrm{n}=17)$, ductal carcinoma in situ, grades 1,2 and 3 (DCIS, $\mathrm{n}=10$ ) and infiltrating ductal carcinoma, grades 1,2 and 3 (IDC, $\mathrm{n}=15$ ). Breast lesions were diagnosed by the pathology service of the same institution and the study was carried out with the permission

Table I: Histological characterization of the breast proliferative diseases

\begin{tabular}{ccc}
\hline Cases & Age range & Number of cases \\
\hline Normal breast (NB) & $29-67$ & 8 \\
Florid hyperplasia without atipia (FH) & $32-71$ & 17 \\
Fibroadenoma (FIB) & $30-60$ & 17 \\
Ductal carcinoma in situ (DCIS) & $29-69$ & 10 \\
Infiltrative ductal carcinoma (IDC) & $41-72$ & 15 \\
\hline
\end{tabular}


of the Ethics Committee of the Federal University of Minas Gerais.

\section{Immunohistochemistry}

Immunohistochemistry (IHC) was performed on $5-\mu \mathrm{m}$ sections that were mounted on gelatinized slides, deparaffinized and rehydrated through graded concentrations of ethanol, followed by endogenous peroxidase blockage by the use of $3 \% \mathrm{H}_{2} \mathrm{O}_{2}$ in methanol solution. Then, sections were washed in PBS and incubated with normal rabbit serum for $1 \mathrm{~h}$ to block non-specific binding sites. The sections were incubated with the primary antibodies in $0.1 \% \mathrm{BSA} / \mathrm{PBS}$ at $4{ }^{\circ} \mathrm{C}$ overnight at a final dilution of 1:200. Primary polyclonal antibodies raised against human antigens used in the present experiment were: rabbit anti-FST kindly donated by Dr. Wylie Vale (Salk Institute, La Jolla, USA) as previously described [21-23] and rabbit anti-FLRG kindly donated by Dr Véronique Maguer-Satta (Centre Léon Bérard, Lyon, France) $[21,22,24,25]$. Subsequently, biotinylated secondary antibodies were added to the sections during $30 \mathrm{~min}$ followed by peroxidase streptavidin incubation in $\mathrm{ABC}$ reagent (Vectastain Elite Universal Kit - Vector Laboratories, Burlingame CA, EUA). Diaminobenzidine (DAB - Sigma Chemicals. CO, St Louis, MO, USA) was successively used in order to visualize the immunolocalization of the primary antibodies. Tissue slices were counterstained with hematoxylin (Sigma Chemicals). Negative control slices were incubated with normal serum instead of primary antibodies.

\section{Probe preparation}

FST and FLRG in situ hybridization probes $[21,22,25]$ were prepared according to the procedure previously described [26] and modified [27]. cDNA obtained from healthy endometrium was amplified by PCR using $200 \mathrm{ng}$ of primers for FST, FLRG, and the internal control genes $\beta$ actin and GAPDH, all presented in Table 2. FST, FLRG, $\beta$ actin and GAPDH amplicons were then labelled with the digoxigenin (Dig), Dig-labelled dUTP (Dig-11-UTP, Boehringer Mannheim, Mannheim, Germany).

\section{In situ hybridization}

In situ hybridization (ISH) was performed according to modifications of the method previously described [26].
Briefly, the sections were dewaxed, rehydrated, fixed in 4\% paraformaldehyde (for $15 \mathrm{~min}$ ) and predigested with proteinase $\mathrm{K}(3 \mathrm{mg} / \mathrm{ml}$ in Tris-EDTA - Boehringer Mannheim) (for $12 \mathrm{~min}$ at $37^{\circ} \mathrm{C}$ ). After acetylation in $0.25 \%$ acetic anhydride in triethanolamine, permeabilization with $(0,1 \mathrm{M}, \mathrm{pH} 7.4)$ phosphate buffer saline (PBS)/Triton (X100) and ethanol dehydration, slides were ready to be hybridized. The sections were incubated with hybridization solution, which contained approximately $13 \mathrm{ng} / \mathrm{ml}$ DIG-labelled probes in hybridization buffer $(30 \%$ of $100 \%$ deionized formamide - Boehringer Mannheim), $20 \% 20 \times$ SSC, $20 \%$ TE, $10 \%$ enatured salmon sperm DNA (10 mg/ml, Boehringer Mannheim), 1\% tRNA (100 mg/ $\mathrm{ml}$; Boehringer Mannheim), and $14 \% \mathrm{H}_{2} \mathrm{O}$. The hybridization solution was incubated at $100^{\circ} \mathrm{C}$ for $5 \mathrm{~min}$, cooled on ice for $10 \mathrm{~min}$ and incubated at $42^{\circ} \mathrm{C}$ overnight. Subsequently, for the immunoperoxidase staining, the sections were incubated with mouse anti-digoxigenin antibodies $(2 \mu \mathrm{g} / \mathrm{ml}$; Boehringer Mannheim) in PBS-3\% BSA for $1 \mathrm{~h}$. After washing in PBS/0,1\% Tween 20, the sections were incubated in rabbit anti-mouse antibodies coupled to peroxidase ( $13 \mu \mathrm{g} / \mathrm{ml}$; DAKO, Milan, Italy) in PBS with 3\% BSA for $30 \mathrm{~min}$. To enhance staining, sections were incubated with swine antibodies against rabbit immunoglobulins coupled to peroxidase $(26 \mu \mathrm{g} / \mathrm{ml}$; DAKO). The immunoreactivity was visualized by DAB chromogen. Negative control procedures were performed to assess the specificity of the ISH signal: 1) omitting Diglabeled probe; 2) omitting anti-Dig antibody; 3 ) omitting Dig-labeled probe and anti-Dig antibody. Slides were counterstained with hematoxylin, dehydrated with alcohol, cleared with xylene and mounted with a coverslip before observation.

\section{Semiquantitative scoring}

Images were acquired and analyzed on a Carl Zeiss Axioplan 2 imaging microscope by AxioCam HR CCD camera and AxioVision 3.1 software (Carl Zeiss, Göttingen, Germany) by three different researchers blinded to patients. For both in situ hybridization and immunohistochemistry, the intensity of epithelium chromogen staining was graded semiquantitatively on a scale of 0-3 arbitrary units with 0 indicating no detectable staining, 1 = weak, 2 = moderate and 3 = strong. The area with positive staining was analyzed using the following scale: $0=$ no detectable

Table 2: Primers and probes used for the in situ hybridization

\begin{tabular}{ccc}
\hline Gene & Primer sequence & Product size \\
\hline \multirow{2}{*}{ FST } & 5'-TGCCACCTGAGAAAGGCTAC-3' & 201 bP \\
FLRG & 5'-ACAGACAGGCTCATCCGACT-3' & 198 bp \\
& 5'-ACCTGAGCGTCATGTACCG-3' & \\
B-actin & 5'-TGTGGCACGAGGAGATGTAG-3' & 308 bp \\
GAPDH & 5'-GAT CAT TGC CCT CCT GAG C-3 & \\
& 5'-CAC CTT CAC CGT TCC AGT TT-3' & 300 bP \\
\hline
\end{tabular}


staining; $1=$ up to $10 \% ; 2=10-50 \%$ and $3=$ more than $50 \%$ of staining.

\section{Statistical analysis}

The area and intensity of IHC and ISH staining for FST and FLRG are presented as medians and ranges, and differences between groups were assessed by Kruskal-Wallis analysis of variance followed by Dunn's test for non-parametric multiple comparisons.

\section{Results}

Clinical samples of the breast proliferative diseases were classified by the consultant pathologist as indicated in the Table 1. In order to determine cellular localization and the expressional profile of FST and FLRG in the normal breast and in different breast proliferative diseases, the tissue structures that were analyzed for mRNA and protein staining were: epithelial cytoplasm, epithelial nuclei and stromal tissue. Tissue localization and staining patterns of FST mRNA and protein are illustrated in Figure 1, with the corresponding semiquantitative analyses depicted in Figure 2. The same is shown for FLRG Figure 3 and Figure 4. FST and FLRG staining localization and patterning were similar for mRNA and protein, demonstrating that transcription and translation were in accordance, and no differences between the three diverse grades of DCIS and IDC analyzed were identified (data not shown).

\section{FST expression and tissue distribution}

Less than $10 \%$ of the cells were stained by the FST probe in the NB group, while for the breast proliferative disorders, $10-50 \%$ of the cells were positive for the probe staining. FST protein staining was scored between $10-50 \%$ for all the groups analyzed and no differences in the area of staining were observed for FST in the different stages of tumor progression examined (Figure 2A and 2B). In all groups both epithelial cytoplasm and epithelial nucleus staining were homogeneously distributed throughout the epithelial cells, with a moderate to weak staining pattern, although epithelial nucleus staining was undetected in some cases at the protein level (Figure 2F). No differences of FST intensity staining were detected for the epithelial cytoplasm and epithelial nucleus (Figure 2C and 2F). The stromal staining was weak or undetectable for all the groups but FIB (Fig $1 \mathrm{E}$ and $1 \mathrm{~F}$ ), which showed an increased intensity of staining at both mRNA $(\mathrm{P}=0.033)$ (Figure $2 \mathrm{G}$ ) and protein $(\mathrm{P}=0.032)$ (Figure $2 \mathrm{H}$ ) level, when compared to the NB group. The negative controls of breast tissue showed no staining (Figure $1 \mathrm{~K}$ and $1 \mathrm{~L}$ ).

\section{FLRG expression and tissue distribution}

FLRG staining was present in NB breast tissue and in all breast proliferative diseases analyzed. FLRG staining at mRNA (Figure 4A) and protein (Figure 4B) level was present in less than $10 \%$ of the cells in the NB group and in $10-50 \%$ of the cells in the cases of FH, FIB and DCIS. In
IDC cases, probe and immunostaining was present in more than $50 \%$ of the cells, thus demonstrating a significant increase when compared to the NB group $(\mathrm{P}=0.015$ and $\mathrm{P}=0.017$, for mRNA an protein staining, respectively). Both epithelial cytoplasm and epithelial nucleus showed weak to moderate staining for all the groups but IDC, where the diffusely infiltrated small and irregular epithelial cells showed strong staining at mRNA and protein level. Conversely, the stromal cells showed a weak pattern of staining at mRNA and protein levels (Figure 3A and 3J). Regarding the pre-neoplastic diseases analyzed, FLRG intensity in the epithelial cytoplasm and nucleus were not different from the control group. On the other hand, FLRG staining intensity was stronger in the epithelial cytoplasm of the IDC at mRNA (Figure 4C, P = 0.007) and protein (Figure 4F, $\mathrm{P}=0.008$ ) levels and in the epithelial nucleus for both mRNA $(\mathrm{P}=0.016)$ and protein $(\mathrm{P}=$ $0.037)$. No statistically significant changes in the stromal intensity were observed in all the proliferative diseases analyzed (Figure 4G and $4 \mathrm{H}$ ).

\section{Discussion}

In the present paper we first demonstrated that human breast proliferative disorders such as FH, FIB and DCIS, express FST and FLRG and confirmed previous findings describing FST and FLRG expression in NB and IDC [17]. In the NB and in all the breast proliferative disorders analyzed, FST and FLRG were localized in the epithelial and in the stromal cells at mRNA and protein levels. These expressional patterns are similar to the one we $[2,28]$ and others [4] previously described for activin in human normal and pathological breast tissues. Here we also found an increased expression of FST in stromal cells of FIB compared to NB and FLRG up regulation in IDC.

FIB are benign tumors of the breast typically composed of stromal and epithelial cells [29] and we previously reported that activin $\beta \mathrm{A}$ was down regulated in this breast disease [2]. Taken together, the findings that demonstrate down regulation of activin $\beta$ A and up regulation of FST in FIB suggest that activin anti-proliferative effects may be weakened, thus favoring the cellular events that lead to the establishment of the FIB lesion. Additionally, in a mouse model, Krneta and co-workers (2006) [20] showed that although FST-expressing R30C tumors displayed increased angiogenesis, they were highly susceptible to undergo serum starvation-induced apoptosis, suggesting a role for FST in limiting tumor progression. Moreover, despite some controversy about the importance of hormonal effects in the development of FIB, some reports documented increased estradiol levels in the serum of women carrying FIB lesions [29]. In this connection, FST mRNA transcripts were decreased in the mammary gland of rats after ovariectomy, showing that FST expression is regulated by estrogen in the mammary gland [30]. 

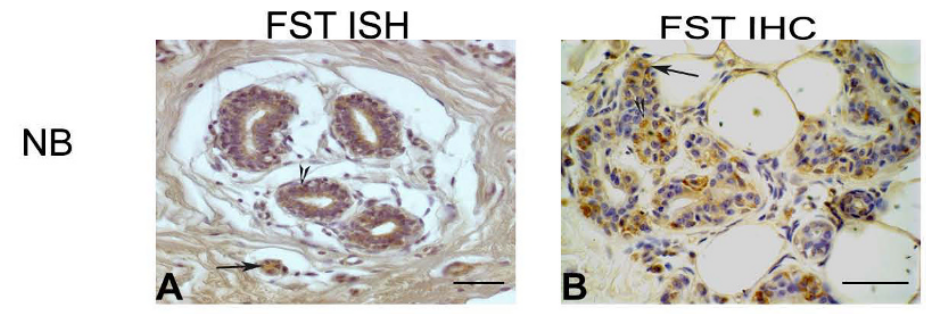

$\mathrm{FH}$
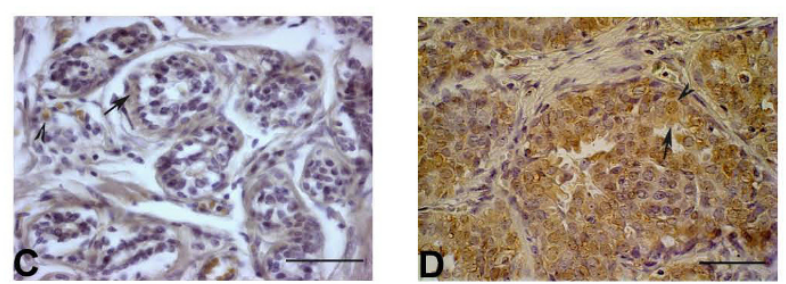

FIB
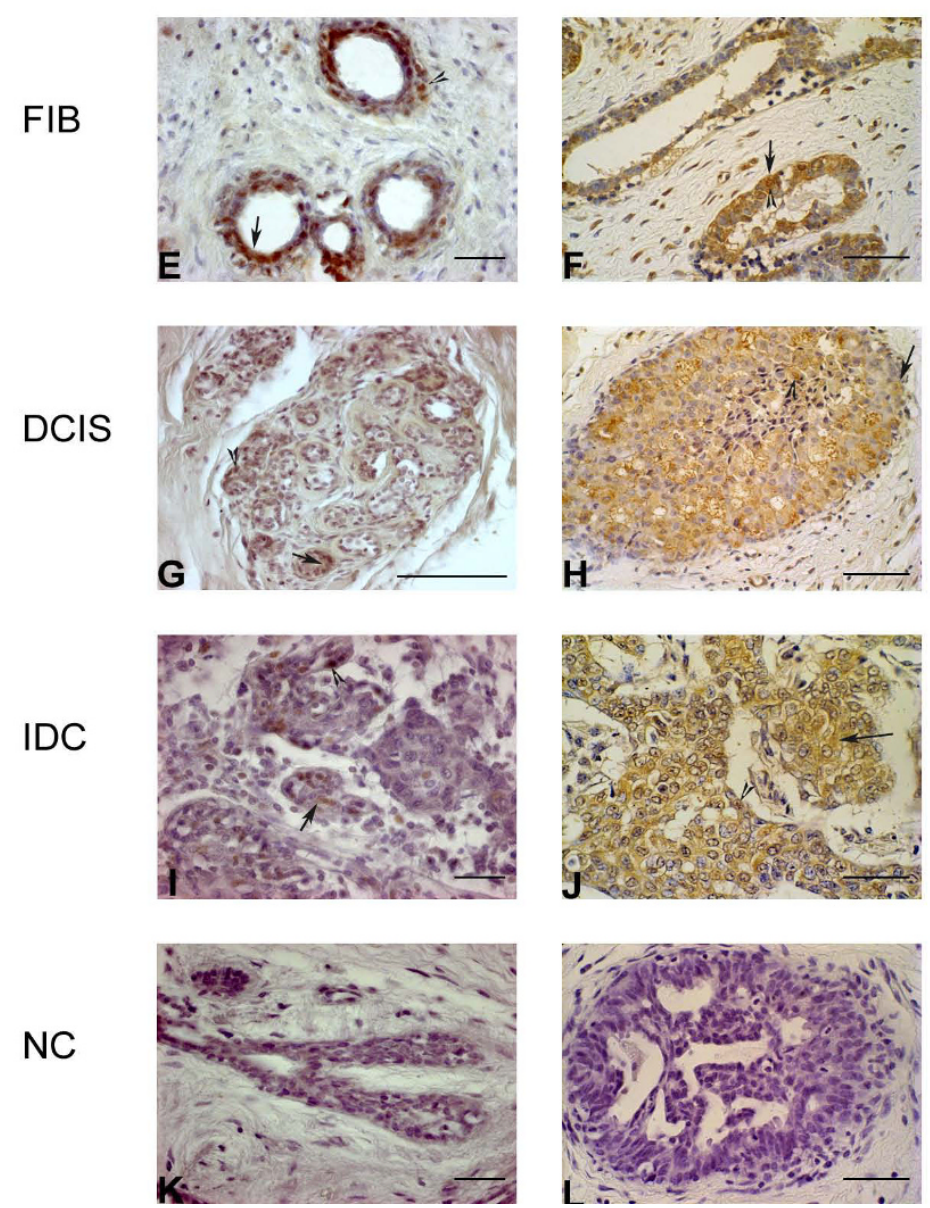

Figure I

Follistatin representative microscopic views of: mRNA expression (A, C, E, G, I) as detected by in situ hybridization (ISH); and protein expression (B, D, F, H, J) as identified by immunohistochemistry (IHC) for normal breast (NB), florid hyperplasia (FH), fibroadenoma (FIB), ductal carcinoma in situ (DCIS) and invasive ductal carcinoma (IDC). FST staining was detected in the epithelial cytoplasm (arrow) and nucleus (arrowhead) in the normal, benign and malignant breast tissue, with a stronger staining in the FIB peri-alveolar stromal cells. Negative controls were performed omitting anti-Dig antibody; Dig-labelled probe and anti-Dig antibody for ISH (K) and omitting the primary antibody for IHC (L). Bar $50 \mu \mathrm{m}$. 

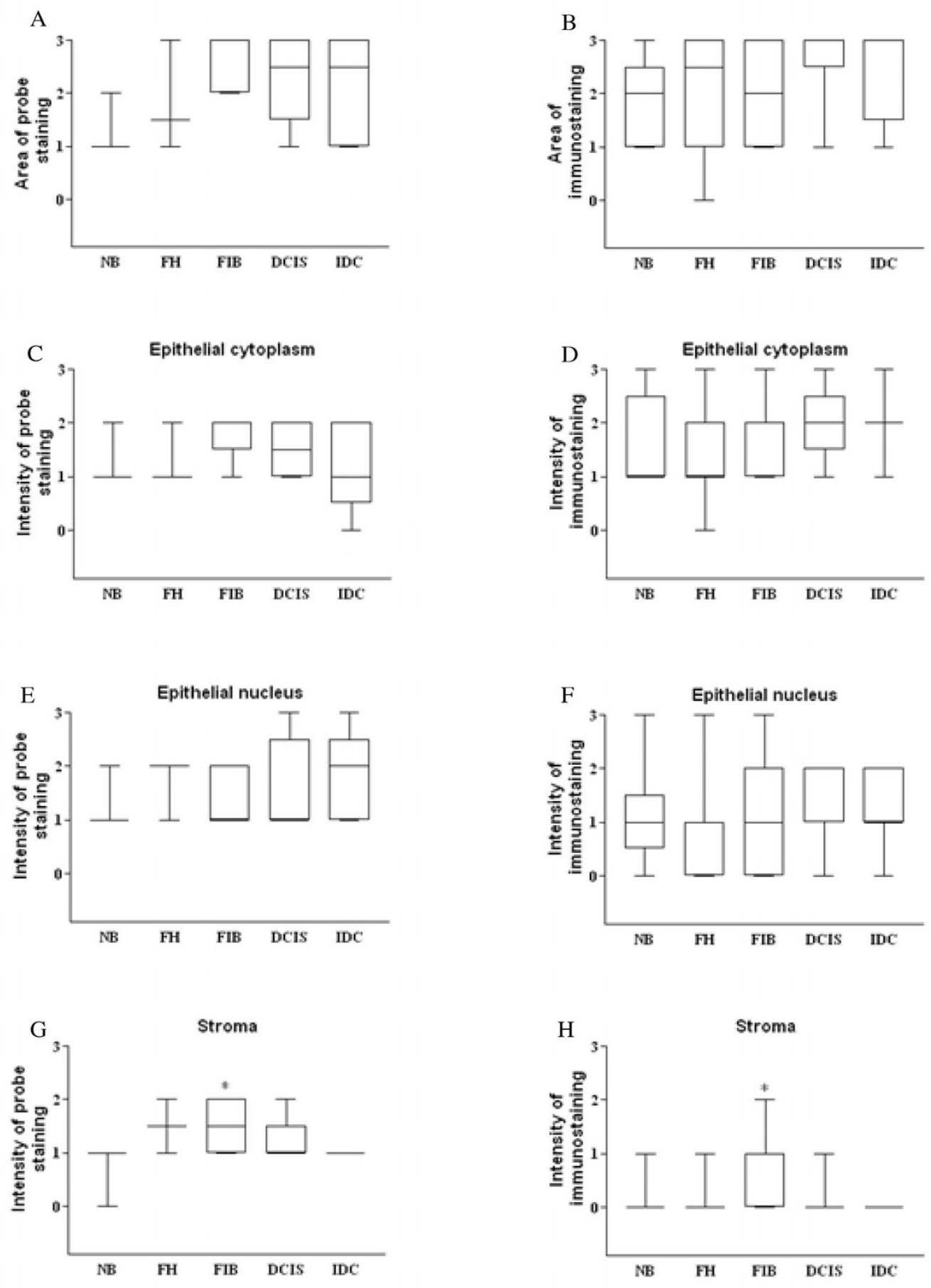

\section{Figure 2}

FST diagrammatic presentation of semi-quantitative data for normal, benign and malignant breast tissue. FST expression was analyzed by in situ hybridization $(\mathbf{A}, \mathbf{C}, \mathbf{E}, \mathbf{G})$ and immunohistochemistry $(\mathbf{B}, \mathbf{D}, \mathbf{F}, \mathbf{H}$,$) in the normal breast (\mathbf{N B})$, florid hyperplasia (FH), fibroadenoma (FIB), ductal carcinoma in situ (DCIS) and infiltrative ductal carcinoma (IDC). FST stromal intensity was stronger in the FIB; * $P 0.05$ compared to NB (Kruskal-Wallis followed by Dunn's test). 

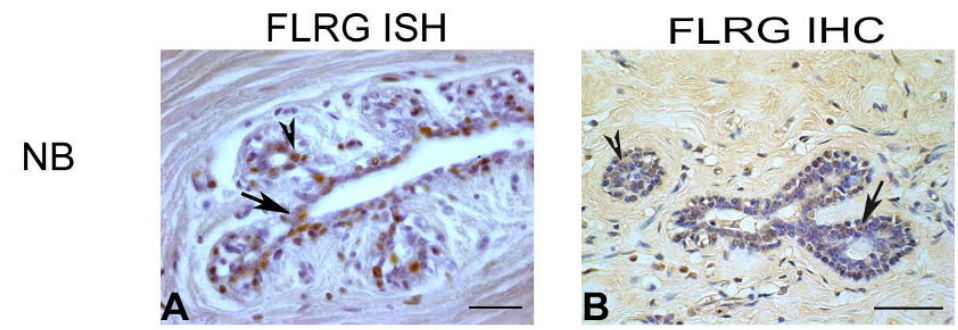

$\mathrm{FH}$
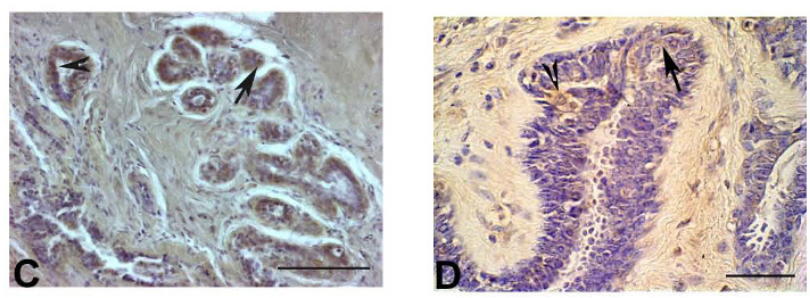

FIB
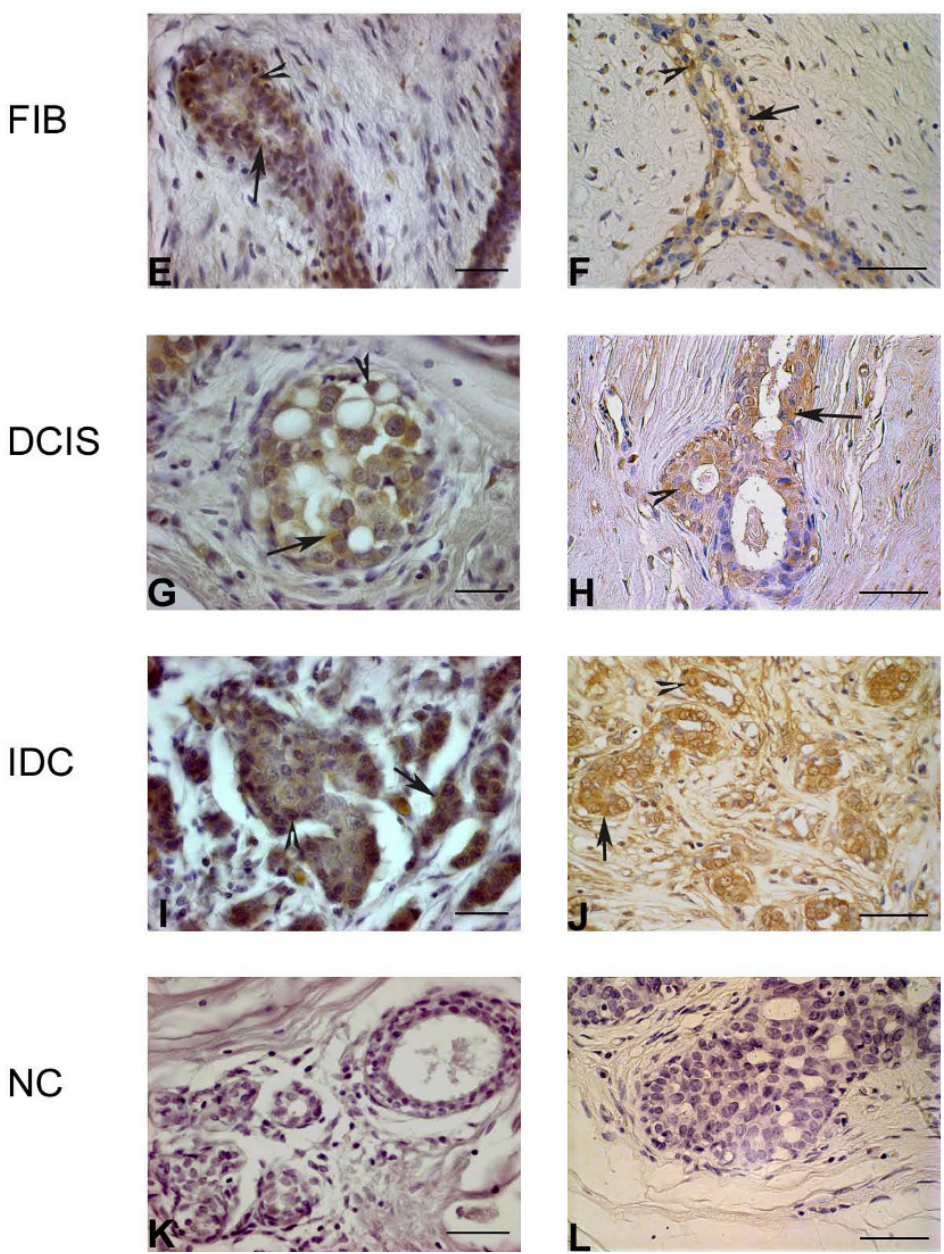

Figure 3

FLRG representative microscopic views of: mRNA (A,C,E,G,I) and protein (B,D,F,H,J) expression detected by in situ hybridization (ISH); and immunohistochemistry (IHC), respectively, in normal breast (NB), florid hyperplasia (FH), fibroadenoma (FIB), ductal carcinoma in situ (DCIS) and infiltrative ductal carcinoma (IDC). FLRG staining was detectable in the epithelial cytoplasm (arrow) and nucleus (arrowhead) in all the cases analyzed, with some weak staining detected in the stromal cells. $\mathbf{K}$ and L: negative controls for ISH and IHC respectively. Bar $50 \mu \mathrm{m}$. 

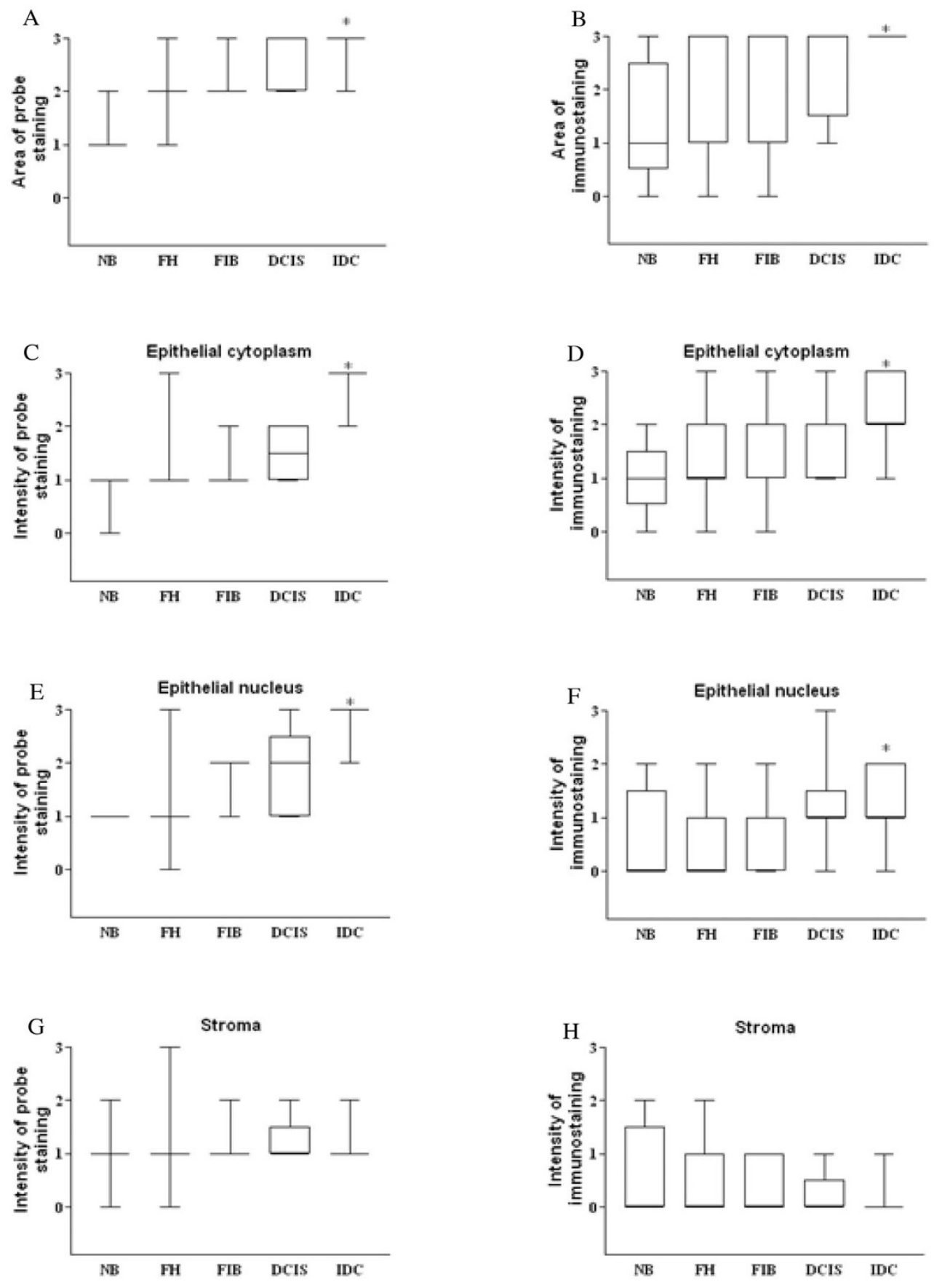

Figure 4

FLRG diagrammatic presentation of semi-quantitative data for normal, benign and malignant breast tissue. FLRG expression was analyzed by in situ hybridization $(\mathbf{A}, \mathbf{C}, \mathbf{E}, \mathbf{G})$ and immunohistochemistry $(\mathbf{B}, \mathbf{D}, \mathbf{F}, \mathbf{H}$,$) in normal breast$ (NB), florid hyperplasia (FH), fibroadenoma (FIB), ductal carcinoma in situ (DCIS) and infiltrative ductal carcinoma (IDC). FLRG area of staining was augmented in the IDC, correspondingly, epithelial cytoplasm and nuclear staining was stronger in the IDC; *p 0.05 compared to NB (Kruskal-Wallis followed by Dunn's test). 
Regarding FLRG, in the present study, we found that its expression was increased in IDC at protein level as previously reported [17] and that such increased expression was also present at mRNA level, implying that the tumor itself is the source of increased FLRG protein expression. Concerning activin's role in breast cancer, previously we reported an increased transcript profile of activin $\beta \mathrm{A}$ subunit and an augmented activin A concentration in homogenates of breast carcinoma [3]. On the other hand, in high grade breast cancer, an impairment of the activin signal transduction system has been linked to oncogenic progression, since a reduced expression of activin $\beta \mathrm{B}$ and its receptors, as much as alterations of smad signaling have been characterized [4]. All in all, together with the findings that FLRG contributes to tumor cell proliferation through antagonizing activin effects [17], we assume that the increased activin A expression reported in breast carcinoma is counteracted by an increased FLRG expression that prevents activin from binding its receptors and thus reducing smad signaling and activin anti-proliferative effects. Additionally, we also analyzed FLRG pattern of expression in pre-neoplastic diseases and in DCIS, a lesion where cancer cells do not infiltrate the adjacent stromal tissue and which has been pointed to be a precursor of IDC [31]. FLRG was only over-expressed in the IDC, suggesting that FLRG is strongly correlated with tumor progression and breast malignancy.

As for the cellular localization, the typical nuclear staining of FLRG already described in other cell types [32] was present in the normal and pathologic mammary glands evaluated here. We also observed FLRG staining in the cytoplasm, which recapitulates in vivo observations in human endometrium [21,25]. In the current study, FST staining was stronger in the cytoplasm, suggesting that the localization pattern of this protein in mammary gland epithelial cells is the same already described for other tissues [22,33]. Yet, we also noted nuclear staining of FST, which is rather atypical but has been described before in spermatogenic cells [34].

It is interesting to note that FST expression was increased in the stromal cells of FIB, while FLRG was up regulated in IDC, indicating that the two activin binding proteins may play diverse roles in tumor progression. Although their overall gene structure is quite similar, FST and FLRG seem to regulate activin pathway in different ways [35]. Indeed, in human liver tumor specimens, FST expression was increased in about $60 \%$ while FLRG transcript profile remained unchanged [18]. Conversely, in endometrial carcinoma, FST expression is unchanged while FLRG expression is down-regulated [21]. FLRG was also found to be down-regulated in ovarian endometriosis, while FST expression was found to be up-regulated [22]. Collectively, these finds demonstrate a number of differences between FST and FLRG, further suggesting that they may not be complete functional homologues.

Finally, a further mechanism to be hypothesized is that activin may have, similarly to TGF $\beta$, a dual role on cancer progression. In early phase, TGF- $\beta$ inhibits growth of cancer cells by cytostasis, differentiation and apoptosis. In later phase, instead, it works to promote cancer progression and metastasis by several mechanisms including evasion from immunological recognition, production of growth factors, differentiation into an invasive phenotype, metastatic dissemination as much as the establishment and dispersion of metastatic colonies [36,37]. Although whether activins work similar to TGF- $\beta$ is not currently known, despite the anti-proliferative actions of activin, follistatin seems to act as an inhibitor of cancer metastasis [19].

\section{Conclusion}

The current findings suggest a role for FST in breast benign disease, particularly in FIB, since its expression was increased in the stromal cells of this benign disease. Moreover, given that both FLRG mRNA and protein are up regulated in IDC, we conclude that the tumor is the source of the increased FLRG peptide in this invasive carcinoma. In addition, since FLRG expression is not altered in DCIS, but only in IDC, we conclude that FLRG may play an important role towards malignancy. As activin displays an anti-proliferative effect in human mammary cells, the present findings indicate that increased FST and FLRG expression in breast proliferative diseases might counteract the anti-proliferative effects of activin.

\section{Competing interests}

The authors declare that they have no competing interests.

\section{Authors' contributions}

EB, HLC, LM, PC, MM, and LEB carried out the experiments described in the study. VFA and GDC reviewed the pathological diagnosis of the breast samples while the present study was designed and analyzed by MM, GG, FP and FMR. All authors read and approved the final manuscript.

\section{Acknowledgements}

The authors wish to thank Dr Wylie Vale (Salk Institute, La Jolla, USA), for donating FST primary antibody; Dr Véronique Maguer-Satta (Centre Léon Bérard, Lyon, France) for donating FLRG primary antibody.

\section{References}

I. Risbridger GP, Schmitt JF, Robertson DM: Activins and inhibins in endocrine and other tumors. Endocr Rev 200I, 22:836-858.

2. Di Loreto C, Reis FM, Cataldi P, Zuiani C, Luisi S, Beltrami CA, Petraglia F: Human mammary gland and breast carcinoma contain immunoreactive inhibin/activin subunits: evidence for a secretion into cystic fluid. Eur J Endocrinol 1999, I 4I:190-194.

3. Reis FM, Cobellis L, Tameirao LC, Anania G, Luisi S, Silva IS, Gioffre W, Di Blasio AM, Petraglia F: Serum and tissue expression of 
activin A in postmenopausal women with breast cancer. J Clin Endocrino Metab 2002, 87:2277-2282.

4. Jeruss JS, Sturgis CD, Rademaker AW, Woodruff TK: Down-regulation of activin, activin receptors, and Smads in high-grade breast cancer. Cancer Res 2003, 63:3783-3790.

5. Liu QY, Niranjan B, Gomes P, Gomm J], Davies D, Coombes RC Buluwela L: Inhibitory effects of activin on the growth and morpholgenesis of primary and transformed mammary epithelial cells. Cancer Res 1996, 56: I I55- I I63.

6. Burdette JE, Jeruss JS, Kurley SJ, Lee El, Woodruff TK: Activin A mediates growth inhibition and cell cycle arrest through Smads in human breast cancer cells. Cancer Res 2005, 65:7968-7975.

7. Burdette JE, Woodruff TK: Activin and estrogen crosstalk regulates trancriptional and cell cycle control in human breast cancer cells. Endocr Relat Cancer 2007, 14:679-689.

8. Lin SJ, Lerch TF, Cook RW, Jardetzky TS, Woodruff TK: The structural basis of TGF-beta, bone morphogenetic protein, and activin ligand binding. Reproduction 2006, 132:179-190.

9. Komatsu Y, Scott G, Nagy A, Kaartinen V, Mishina Y: BMP type I receptor ALK2 is essential for proper patterning at late gastrulation during mouse embryogenesis. Dev Dyn 2007, 236:5I2-5I7.

10. Harrison CA, Gray PC, Vale WW, Robertson MD: Antagonists of activin signaling: mechanisms and potential biological applications. Trends Endocrinol Metab 2005, 16:73-78.

II. Hashimoto O, Tsuchida K, Ushiro Y, Hosoi Y, Hoshi N, Sugino H, Hasegawa $Y$ : cDNA cloning and expression of human activin betaE subunit. Mol Cell Endocrinol 2002, 194:1 I7-122.

12. Schneyer A, Schoen A, Quigg A, Sidis Y: Differential binding and neutralization of activins $A$ and $B$ by follistatin and follistatin like-3 (FSTL-3/FSRP/FLRG). Endocrinology 2003, | 44: | 67|-1674.

13. Glister C, Kemp CF, Knight PG: Bone morphogenetic protein (BMP) ligands and receptors in bovine ovarian follicle cells: actions of BMP-4, -6 and -7 on granulosa cells and differential modulation of Smad-I phosphorylation by follistatin. Reproduction 2004, I 27:239-254.

14. Lee SJ, Mcpherron AC: Regulation of myostatin activity and muscle growth. Proc Natl Acad Sci 200 I, 98:9306-93II.

15. Hill JJ, Davies MV, Pearson AA, Wang JH, Hewick RM, Wolfman NM, Qiu Y: The myostatin propeptide and the follistatin-related gene are inhibitory binding proteins of myostatin in normal serum. J Biol Chem 2002, 277:40735-4074I.

16. Chen YG, Wang Q, Lin SL, Chang CD, Chuang J, Ying SY: Activin signaling and its role in regulation of cell proliferation, apoptosis, and carcinogenesis. Exp Biol Med 2006, 231 :534-544.

17. Razanajaona D, Joguet S, Ay AS, Treilleux I, Goddard-Leon S, Bartholin L, Rimokh R: Silencing of FLRG, an antagonist of activin, inhibits human breast tumor cell growth. Cancer Res 2007, 67:7223-7229.

18. Deli A, Kreidl E, Santifaller S, Trotter B, Seir K, Berger W, SchulteHermann R, Rodgarkia-Dara C, Grusch M: Activins and activin antagonists in hepatocellular carcinoma. World J Gastroenterol 2008, 21:1699-1709.

19. Ogino H, Yano S, Kakiuchi S, Muguruma H, lkuta K, Hanibuchi M, Uehara H, Tsuchida K, Sugino H, Sone S: Follistatin suppresses the production of experimental multiple-organ metastasis by small cell lung cancer cells in natural killer cell-depleted SCID mice. Clin Cancer Res 2008, 14:660-667.

20. Krneta J, Kroll J, Alves F, Prahst C, Sananbenesi F, Dullin C, Kimmina $S$, Phillips DJ, Augustin HG: Dissociation of angiogenesis and tumorigenesis in follistatin- and activin-expressing tumors. Cancer Res 2006, 66:5686-5695

21. Ciarmela P, Florio P, Sigurdardottir M, Toti P, Maguer-Satta V, Rimokh R, Altomare A, Tosi P, Petraglia F: Follistatin-related gene expression, but not follistatin expression, is decreased in human endometrial adenocarcinoma. Eur J Endocrinol 2004 | 5 |:25|-257.

22. Torres PB, Florio P, Ferreira MC, Torricelli M, Reis FM, Petraglia F: Deranged expression of follistatin and follistatin-like protein in women with ovarian endometriosis. Fertil Steril 2007, 88:200-205

23. Ferreira MC, Cavallo IK, Florio P, Petraglia F, Reis FM: Activin betaA subunit, follistatin and follistatin-like 3 are expressed in the endometrium of ovariectomized rats and regulated by estrogen replacement. J Mol Histol 2008, 39:535-54 I.

24. Maguer-Satta V, Bartholin L, Jeanpierre S, Gadoux M, Bertrand S, Martel S, Magaud JP, Rimokh R: Expression of FLRG, a novel activin
A ligand, is regulated by TGF-beta and during hematopoiesis. Exp Hematol 200I, 29:30I-308.

25. Florio P, Ciarmela P, Toti P, Maguer-Satta V, Rimokh R, Buonocore G, Rossi M, Gioffrè W, Petraglia F: Human endometrium and decidua express follistatin-related gene (FLRG) MRNA and peptide. Mol Cell Endocrinol 2004, 21 8: I 29-। 35.

26. Klein SC, van Wichen DF, Golverdingen JG, Jacobse KC, Broekhuizen $R$, de Weger RA: An improved, sensitive, non-radioactive in situ hybridization method for the detection of cytokine mRNAs. APMIS 1995, 103:345-353.

27. Massai L, Carbotti P, Cambiaggi C, Mencarelli M, Migliaccio P, Muscettola M, Grasso G: Prepro-endothelin-I mRNA and its mature peptide in human appendix. Am J Physiol Gastrointest Liver Physiol 2003, 284:340-348.

28. Reis FM, Luisi S, Carneiro MM, Cobellis L, Federico M, Camargos AF, Petraglia F: Activin, inhibin and the human breast. Mol Cell Endocrinol 2004, 225:77-82.

29. Courtillot C, Plu-Bureau G, Binart N, Balleyguier C, Sigal-Zafrani B, Goffin V, Kuttenn F, Kelly PA, Touraine P: Benign breast diseases. J Mammary Gland Biol Neoplasia 2005, 10:325-335

30. Bussmann UA, Lanuza GM, Bussmann LE: Activin and follistatin in rat mammary gland. Mol Cell Endocrinol 2004, 30:9-19.

31. Page DL, Dupont WD, Rogers LW, Landenberger M: Intraductal carcinoma of the breast: follow-up after biopsy only. Cancer 1982, 49:75I-758.

32. Saito S, Sidis Y, Mukherjee A, Xia Y, Schneyer A: Differential biosynthesis and intracellular transport of follistatin isoforms and follistatin-like-3. Endocrinology 2005, 146:5052-5062.

33. Refaat B, Amer S, Ola B, Chapman N, Ledger W: The expression of activin-betaA- and -betaB-subunits, follistatin, and activin type II receptors in fallopian tubes bearing an ectopic pregnancy. J Clin Endocrinol Metab 2008, 93:293-299.

34. Ogawa K, Hashimoto O, Kurohmaru M, Mizutani T, Sugino H, Hayashi Y: Follistatin-like immunoreactivity in the cytoplasm and nucleus of spermatogenic cells in the rat. Eur J Endocrinol 1997 , 137:523-529.

35. Welt $\mathrm{C}$, Sidis $\mathrm{Y}$, Keutmann $\mathrm{H}$, Schneyer A: Activins, inhibins, and follistatins: from endocrinology to signaling. A paradigm for the new millennium. Exp Biol Med 2002, 227:724-752.

36. Kang Y, Siegel PM, Shu W, Drobnjak M, Kakonen SM, Cordón-Cardo C, Guise TA, Massagué J: A multigenic program mediating breast cancer metastasis to bone. Cancer Cell 2003, 3:537-49.

37. Massagué J: TGFbeta in Cancer. Cell 2008, 134:215-30.

\section{Pre-publication history}

The pre-publication history for this paper can be accessed here:

http://www.biomedcentral.com/1471-2407/9/320/pre pub

Publish with Biomed Central and every scientist can read your work free of charge

"BioMed Central will be the most significant development for disseminating the results of biomedical research in our lifetime. "

Sir Paul Nurse, Cancer Research UK

Your research papers will be:

- available free of charge to the entire biomedical community

- peer reviewed and published immediately upon acceptance

- cited in PubMed and archived on PubMed Central

- yours - you keep the copyright
BioMedcentral 